\title{
The contribution of prenatal stress to the pathogenesis of autism as a neurobiological developmental disorder: a dizygotic twin study
}

\author{
M. Claassen; H. Naudé; E. Pretorius; M. C. Bosman
}

\begin{abstract}
This paper reports on the contribution of prenatal stress to the pathogenesis of autism as a neurobiological developmental disorder in a dizygotic study. The aim was to explore whether the neurobiological impact of stress prior to week 28 of gestation might be related to the pathogenesis of autism. The following data-generating strategies were employed: a diagnostic stress inventory, the 16-Personality Factor Questionnaire, magnetic resonance imaging and blood plasma sampling. It was found that maternal stress during pregnancy may have produced elevated leucocytes and glucocorticoids during gestation, because stress affects cellular immunity due to involvement of the hipothalamic-pituary-adrenal axis. These were implicated in suboptimal placental functioning, heightened exposure of the foetus to glucocorticoids and altered neural development. The autistic subject's blood plasma pathology results showed elevated glucocorticoids and serotonin. Significant cortisol and serotonin differences were noted in the blood plasma pathology results of the autistic subject and the control. Hyperserotonemia and elevated glucocorticoids were therefore implicated in altered programmed neural development, as suggested by the autistic subject's magnetic resonance images. Differences in head circumference were also noted. It was concluded that prenatal maternal stress might have significantly contributed to the pathogenesis of autism.
\end{abstract}

Keywords: Autism; Developmental disorder; Dizygotic twin study; Glucocorticoids; Head circumference; Pathogenesis; Prenatal stress; Serotonin

\section{Introduction}

The contribution of prenatal stress to the pathogenesis of autism as a neurobiological developmental disorder was explored in this research project. Autism is characterised by serious functional impairment pertaining to socialisation, communication and imagery (Panksepp, 1998, Trevarthen, 2000 Kates et al., 2004). In 1943, Kanner established the concept of autism (also known as Kanner's autism) and remarked that children with autism '... have come into the world with an innate inability to form the usual, biologically provided affective contact with people' (Kanner, 1943 cited in Panksepp, 1998, p. 276). The term autism is used to describe these individuals' withdrawal from social interaction, since the Greek term 'autos' means 'self' (Herman, 1996). After a period during which claims were made that autism is caused by faulty parenting, researchers are currently united in their view that autism is primarily a neurobiological developmental disorder (Bauman \& Kemper, 1994; Herman, 1996; Panksepp, 1998; Trevarthen, 2000;; Clark, 2002; Courchesne, 2002; Keller \& Persico, 2003; Schmidt \& Rotenberg, 2005). 
Research findings suggest that this neurobiological developmental disorder might be ascribed to disrupted neural development during the second trimester of gestation when the foetal brain stem, cerebellum and limbic pathways are generated (Bauman \& Kemper, 1995).

In keeping with these findings, Beversdorf in 2004 pointed out a significant relation between prenatal stress and the development of autism (Beversdorf, 2004). The neurobiological impact of stress prior to the 28th week of gestation might produce structural neural changes, specifically regarding the cerebellum, the brain stem and limbic pathways, including the hippocampal area (Sapolsky, 2000). Sapolsky (2000) found that programmed apoptosis is affected due to the neurobiological impact of stress on foetal development, a concept that relates closely to the pathogenesis of autism. Sapolsky (2000) established that increased levels of cortisol in response to chronic stress (maternal or foetal) might kill nerve cells in the hippocampus. If hippocampal activity is thus compromised, excessive cortisol is secreted and, over time, the ability to deactivate the stress response is reduced, which leads to further atrophy of the hippocampus. These findings indicate that chronic stress leading to chronic secretion of cortisol may have long-lasting effects on physical functioning, including brain damage. Programmed apoptosis may be grossly interfered with, especially within the areas of the hippocampus and the cerebellum. Magnetic resonance (MR) imaging confirmed structural differences of the cerebellum, the brain stem and limbic system associated with autism (Beversdorf, 2004), and these structural differences were further associated with elevated levels of glucocorticoids and endogenous opiates during gestation (Bertram \& Hanson, 2002). Elevated glucocorticoids inhibit foetal growth and are associated with altered programmed foetal cortical development (Bertram \& Hanson, 2002). Thus, there appears to be a link between the pathogenesis of autism and prenatal endogenous and exogenous glucocorticoids as well as endogenous opiates (Panksepp, 1998).

In this research project a significant focus is placed on prenatal hipothalamic-pituaryadrenal (HPA) activity due to the HPA axis' interactivity with cortisol, adrenalin, noradrenalin and serotonin (Kurup \& Kurup, 2003), as these hormones are significantly implicated in programmed foetal development, postnatal cortical behaviour, postnatal learning as well as in functional impairment of socialisation, communication and imagery associated with autism (American Psychiatric Association [APA], 2000).

Recently, various studies concerning monozygotic twins have been undertaken in order to investigate the neurobiological and cortical similarities and differences between children with and without autism (Trevarthen, 2000; Clark, 2002; Courchesne, 2002; Bertram \& Hanson, 2002; Kurup \& Kurup, 2003; Keller \& Persico, 2003; Beversdorf, 2004; Schmidt \& Rotenberg, 2005). This research project differs from previous studies by tracking the neurobiological and cortical differences and similarities in a pair of dizygotic twins, where only one of the pair meets the criteria for autism outlined in the DSM-IVTR (APA, 2000). Dizygotic twins develop from two different ova that were fertilised at the same time. Consequently, these dizygotic siblings share no more genetic similarities than normal siblings (Plug et al., 1987). The reason why a dizogotic twin study was decided upon was to explore whether HPA activity manifests differently among a pair of 
dizogotic siblings, since it is expected that both dizygotic foetuses were exposed to elevated glucocorticoids during gestation, yet only one of the siblings is affected and meets the diagnostic criteria for autism. In addition, a dizygotic twin study offers the ideal research control, since all significant variables are uniform and constant. If prenatal stress does play a role in the pathogenesis of autism, why was only one sibling affected? This phenomenon might only be explained by means of a neurobiological enquiry that forms the basis for a neuropsychological explanation of this complex phenomenon.

\section{Rationale for the study and analysis of the research problem}

The rationale is that all human beings come into the world with a variety of abilities; that is, intrinsic psycho-behavioural control systems that do not require previous learning, but that provide immediate opportunities for learning to occur (Panksepp, 1998). Specific hormones activate these intrinsic psycho-behavioural control systems during gestation, as well as postnatally. When these intrinsic psycho-behavioural control systems are overtaxed or operate outside the normal range, it might result in cortical impairment associated with psychiatric or mental disorders, in keeping with the diagnostic criteria for autism (APA, 2000). Some disorders such as autism and schizophrenia appear to emerge from lesioned brain areas and associated brain circuitry (Kolb \& Whishaw, 2003). Consequently, a substantive understanding of the neurobiological systems and the manner in which they can become compromised or overtaxed prenatally and postnatally might contribute to a better understanding of autism as a neurobiological developmental disorder. The concept neurobiological refers to the study of '... a diversity of coherently operating brain systems which can generate psychologically meaningful classes of adaptive behavioural tendencies' (Panksepp, 1998). In addition, the concept neurobiological also refers to the study of neural pathways and related electrophysiological and neurochemical activities. One of the best examples of neurochemistry comes from research findings implicating the role of serotonin in controlling human mood, including aggression and depression (Young, 1996). Based upon the preceding premise, it is essential to synthesise biological, psychological and neurological perspectives on the pathogenesis of autism.

Autism is characterized by markedly abnormal or impaired development in social interaction and communication and a markedly restricted repertoire of activity and interests. The impairment in reciprocal social interaction is gross and sustained. The impairment in communication is also marked and sustained and affects both verbal and nonverbal skills. (APA, 2000, p. 70)

This brief description of impairment relates to a compromised neural substrate, in keeping with affective neuroscience-which deals with pre-neurological and postneurobiological development. In addition, if speech does develop in children with autism, the pitch, intonation, rate, rhythm or stress may be abnormal (APA, 2000), which points to compromised neural involvement, specifically cerebellum involvement (Naudé et al., in press). Autism is characterised by developmental delays, in keeping with compromised or overtaxed neurobiological systems, which seems to occur prenatally, as suggested by various researchers (Trevarthen, 2000; Clark, 2002; Courchesne, 2002; Bertram \& 
Hanson, 2002; Kurup \& Kurup, 2003; Keller \& Persico, 2003; Beversdorf, 2004; Schmidt \& Rotenberg, 2005).

The following principles thus underlie the rationale for this research project; namely, developmental delay or a total lack of mastery of certain developmental skills characterise autism (APA, 2000; Kolb \& Whishaw, 2003). It is suggested that this developmental delay or lack of mastery of developmental skills might be ascribed to compromised neural development during the second trimester of gestation when the foetal brain stem, cerebellum and limbic pathways are generated (Bauman \& Kemper, 1995); research findings point towards a significant relation between prenatal stress and the development of autism (Beversdorf, 2004); autism deals primarily with development in the areas of socialisation, communication and imagery, and exploration of this phenomenon is therefore firmly based in both the affective neuroscience and psychology. If prenatal risk factors associated with the pathogenesis of autism could be identified, such findings might inform health practitioners to better understand and provide for children with autistic disorder. In addition, such data might significantly implicate prevention and treatment regimes (Burd, 1999). The rationale of this study is in keeping with Barlow and Durand's' views:

... we cannot study behavioural, cognitive, or emotional processes without appreciating the contribution of biological and social factors to psychological and psychopathological expression. Thus, we have abandoned the traditional compartmentalized approach to psychopathology. Instead, we use a more accessible approach that accurately reflects the current state of our clinical science. (Barlow \& Durand, 2002, p. 455)

\section{Literature review}

Recent research projects focused on the role of glucocorticoids in programmed foetal development (Benediktsson et al., 1993; Coleman, 1994; Levitt et al., 1996, 2000; Lindsay et al., 1996; Nyirienda et al., 1998; Bertram \& Hanson, 2002; Clark, 2002; Courchesne, 2002). An increase in foetal exposure to maternal glucocorticoids can cause increased glucocorticoid receptor density and disruption of programmed neural development (Lindsay et al., 1996; Bertram \& Hanson, 2002), yet despite these adverse risks it has become common practice to administer glucocorticoids to pregnant mothers to promote foetal maturation of organs if they are in danger of pre-term delivery (Matthews, 2001).

Various studies point to the involvement of the HPA axis in neural programming. The HPA axis is controlled by a classic negative feedback system in which glucocorticoids released into the circulation by the adrenal gland interact with glucocorticoid receptors located in the pituitary, hypothalamus and hippocampus. Thus, over-activity at any stage along this pathway should result in negative feedback to the corticosteroid-releasing hormone corticotrophins in the hypothalamus, and consequent reduced corticosteroidreleasing hormone release. Preclinical research conducted over the past decade has shown that excess levels of glucocorticoids can result in functional and morphological hippocampal changes (Squire \& Zola-Morgan, 1991; Miller et al., 1993; Zola-Morgan \& 
Squire, 1993; Gould, 1994; Sapolsky, 1994; Zola-Morgan et al., 1994; Alvarez et al., 1995). In addition, McEwen ( 1997) noted that hippocampal shrinkage is usually accompanied by deficits in declarative, episodic, spatial and contextual memory performance, in keeping with the associated features of autistic disorder. These hippocampal changes provide a neural substrate for changes in cognitive functioning among children with autistic disorder (APA, 2000). MR imaging revealed decreased benzodiazepine receptor binding in the medial prefrontal cortex, as well as reduced hippocampal volumes due to over-exposure to glucocorticoids (Stein et al., 1997; Villarreal \& King, 2001). In addition to this, positron emission tomography scans demonstrated decreased $\mathrm{N}$-acetyl aspartame ratios and absolute concentrations in the medial temporal lobe and hippocampus, in keeping with the structural brain differences observed in autistic disorder (Panksepp, 1998). Furthermore, functional MR imaging studies demonstrated different patterns of limbic and paralimbic structure activation due to an excess of glucocorticoids. Of theoretical importance are findings of failure to activate the anterior cingulate, as well as amygdaloidal activation during symptom provocation studies, in keeping with similar observations that were made in autistic disorder (Panksepp, 1998). Villarreal and King (2001) suggested that anterior cingulate dysfunction produces failure to inhibit amygdaloidal activation and/or an intrinsic lower threshold of amygdaloidal response to fearful stimuli. These observations are in keeping with research findings implicating disrupted neural development; that is, brain stem, cerebellum, hippocampal and limbic pathway abnormalities among individuals with autistic disorder (Bauman \& Kemper, 1995; Sapolsky, 2000). In addition, Sapolsky ( 2000) found that programmed apoptosis is affected due to the neurobiology of stress, which concept relates closely to the pathogenesis of autism (Kalat, 2001).

Glucocorticoids in the foetus can be derived from three sources: through increasing basal secretion as the foetal adrenal system matures, or in response to foetal stress; from the mother by transplacental transfer; or by maternal glucocorticoids crossing into the foetal blood-brain barrier, with toxic effects on foetal development (Edwards et al., 1993). By allowing the high glucocorticoid concentrations to cross the placenta, the foetal HPA feedback system that regulates the foetal adrenal output may be overwhelmed. Not only will this have an immediate effect on development, but it may also result in long-term 'resetting' of the foetal HPA axis, which may persist into adulthood, because the normal negative feedback system that regulates normal homeostasis is permanently altered (Edwards et al., 1993).

As the foetal HPA axis regulates the response of the foetus to acute episodes of intrauterine stress and is central to other processes such as organ maturation, growth, neural programming, myelination and cardiovascular regulation, any disturbance is likely to affect a wide range of foetal systems (Phillips et al., 2000). In the foetus, glucocorticoids inhibit tissue expansion and growth. Foetal plasma cortisol concentrations are low until late gestation, when the HPA axis is activated to allow for increased secretion of cortisol from the foetal adrenal gland and a progressive increase in cortisol concentrations; consequently, there is a marked cortisol surge prior to delivery (Challis et al., 2001). The rate of foetal growth normally decreases towards term delivery, which may be linked to the increase in plasma cortisol that occurs at this time, because 
high foetal glucocorticoid concentrations reduce the foetal size. Inappropriate activation of the HPA axis or movement of maternal glucocorticoids across the placenta could therefore increase foetal glucocorticoid concentrations, thus influencing foetal growth. Glucocorticoids act as transcription factors with wide-ranging effects during development - therefore a substantial body of literature implicated autism as a genetic disorder. Many genes are activated by glucocorticoids, and any disruption in HPA-axis functioning could thus have subtle or overt effects on development of many tissues in the cardiovascular, pulmonary, renal and central nervous systems (Byrne, 2001).

In addition, prenatal glucocorticoid exposure permanently programmes several central nervous system functions such as dopamine and serotonin sensitivity, as well as hippocampal formation. Prenatal exposure to glucocorticoids was associated with restricted foetal growth, and delayed myelination of the central nervous system. Barbazanges et al. ( 1996) found that prenatal stress in the final third of gestation caused decreased expression of hippocampal mineralocorticoid receptors, but not glucocorticoid receptors. In humans, prenatal stress has been reported to induce mental retardation and sleep disturbances (Shell, 1981; Barbazanges et al., 1996).

Exposure to excessive levels of glucocorticoids during pregnancy is detrimental in terms of brain structure (Uno et al., 1994), and might even alter postnatal cortisol concentrations (Sapolsky, 1996). Most evidence cited is now showing reduced birth weight, head circumference and more severe chronic lung disease (French et al., 1999) among children who were treated with multi-dose glucocorticoids in utero. In addition to structural central nervous system changes due to high levels of glucocorticoids, the neuroendocrine system also seems to be disrupted. Research findings implicate both central nervous system and neuroendocrinological alterations in the pathogenesis of autism (Bertram \& Hanson, 2002).

The preceding literature study suggests that overexposure to glucocorticoidsduring gestation might affect the foetus adversely. Glucocorticoids act as transcription factors with wide-ranging effects on the foetus during gestation. Many genes are activated by glucocorticoids, implying that organogenesis might be partly controlled by glucocorticoids, with specific focus on foetal central nervous system development (Ross et al., 2000; Maden, 2001; Colbert, 2002; Perrotta et al., 2003). In addition, the balanced supply of glucocorticoids to the foetus is essential, especially during the latter stages of gestation, due to the involvement of glucocorticoids in neural growth and cellular differentiation (Zachman, 1995; Debier \& Larondelle, 2005). However, an excess of glucocorticoids might alter central nervous system formation and adversely impact on postnatal sensorimotor learning and cognitive functioning. Disproportionate levels of glucocorticoids have also been implicated in disrupted programmed apoptosis, with specific focus on hippocampal, cerebellar and limbic formation. Structural differences (e.g., densely packed areas and lesser dendritic growth in other areas) are implicated in autistic disorder, and the cerebellum is of particular interest in this regard, due to its involvement in almost all forms of motor learning and vestibular functioning, which areas once again are implicated in autistic disorder. The cerebellum consists of the cerebellar hemispheres, vermis and the flocculi, and forms part of the motor system that 
participates in postnatal sensorimotor functioning. The flocculonodular lobe receives projections from the vestibular system (the sensory receptors in the middle ear) and takes part in the control of balance and eye movements (Kolb \& Whishaw, 2003). Lesions to the midline areas of the cerebellum might disrupt balance, eye movements, upright posture and walking, but do not substantially disrupt other movements such as reaching, grasping and using the fingers (Kolb \& Whishaw, 2003). The inference is that attainment of developmental milestones, particularly crawling and walking, might be delayed due to overexposure to glucocorticoids during gestation. Sensorimotor learning during the early postnatal developmental years might thus be adversely affected, as seen in autism.

Considering the preceding literature on the adverse effects of glucocorticoids during gestation, as well as the structural and functional brain alterations that result from overexposure, it is suggested that prenatal stress might play a significant role in the pathogenesis of autism. The various impairments associated with autism also suggest that excess levels of glucocorticoids might be implicated (i.e. speech deviations such as pitch, intonation, rate, rhythm, odd hand movements and body posture, high threshold for pain, emotionality, abnormalities in sleep, deviant fear response, and so forth) (APA, 2000), because many of these behaviours are mediated by the brain stem, the cerebellum, the hippocampus, the limbic system and its relays. The role of prenatal stress in the pathogenesis of autism is thus explored at hand of a dizygotic twin study, of which only one sibling meets the criteria for autism. The purpose of this research project was to explore at first hand in a dizygotic twin study the contribution of prenatal stress to the pathogenesis of autism as a neurobiological developmental disorder.

The ethics of doing research in developmental disorders deserve special attention and a child-sensitive approach. Informed consent was therefore obtained prior to commencement of the research project.

\section{Research problem statement}

Based upon the rationale of this research project and the conceptualisation of autism as a developmental disorder, the research problem can be formulated as follows:

- In what unique ways does prenatal stress contribute to the pathogenesis of autism as a neurobiological developmental disorder?

\section{Subquestions}

- What blood plasma differences can be observed among the dizygotic twins at hand of blood sampling?

- Does HPA activity manifest differently among this pair of dizygotic siblings?

- Does the MR image of the sibling diagnosed with autism differ in respect of structural brain development from what is normally expected?

- To which periods of prenatal development can these structural differences be related? 
- How do these structural differences account for sensory, motor, cognitive and affective behavioural expression of autism?

\section{Research hypothesis}

The research hypothesis can be formulated as follows:

- Elevation of glucocorticoids due to prenatal stress disrupts programmed foetal development and contributes to the pathogenesis of autism as a neurobiological developmental disorder.

\section{Theoretical framework and paradigmatic perspective}

The research design is firmly embedded in a positivistic paradigm, which is based upon the utilisation of research methods and practices derived from the natural sciences and application of these to the social sciences. In addition, this research project is also rooted in the cognitive science. Eysenck (2001, p. 5) defines the cognitive science as follows:

Cognitive scientists develop computational models to understand human cognition. A good computational model ... allows us to predict behaviour in new situations. This is a clear advantage over many previous theories in cognitive psychology, which were expressed so vaguely that it was not clear exactly what predictions were supposed to follow from them.

Because the cognitive science to a great extent lacks interpretation of the neurobiological systems that underlie affective human behaviour, affective neuroscience developed from the cognitive science and seeks to provide conceptual bridges that can link our understanding of basic neural circuits for the emotions with straightforward cognitive and psychological views of the human mind and, most importantly, developmental disorders first evident in infancy and early childhood. Affective neuroscience is deeply rooted within physiological psychology, behavioural biology and behavioural neuroscience, and provides the modernised umbrella label for various physiological, affective and cognitive psychological approaches to disorders (Panksepp, 1998).

Because of this small psychological window, and because the key emotional circuits are conserved in the human brain, the two can be linked in such a way that we can finally understand the neurobiological underpinnings of our human emotions. (Panksepp, 1998, pp. 14-15)

Affective neuroscience forms the paradigmatic conceptual bridge needed for this research project, since this approach can yield clear empirical predictions in both directions-from neuroscience and neurobiological science to social science, and vice versa (Panksepp 1998). This paradigmatic conceptual bridge might facilitate an in-depth understanding of autism as a neurobiological developmental disorder. 


\section{Research design, methods, materials and procedures}

This research project represents quantitative research, and comprises a single case study of dizygotic twin siblings, a boy and a girl, currently four years seven months of age. The boy was diagnosed with infantile autism, and is the subject of this research project. At the age of three, a paediatrician and at least two psychologists had independently made the diagnosis of infantile autism, and clinical descriptions met the diagnostic criteria set out in the DSM-IV-TR (APA, 2000). The girl shows normal development and serves as the control for comparing different developmental values. Information was obtained from case history data, which included a detailed interview concerning social background, prenatal, perinatal and developmental histories, clinical, neurological and psychological assessment, and blood plasma pathology reports.

The following data-generating strategies were employed. A diagnostic stress inventory was administered to complement the intake interviews with the parents, and obstetric and developmental records of the mother and both siblings were retrieved. Both the mother and father of the dizygotic twins were required to complete the diagnostic stress inventory, because they might have had different perspectives on the significance of various stressors that were endured during pregnancy. In addition, the 16-Personality Factor Questionnaire was administered to the mother, since it is thought that personality might have influenced the way stressors were handled during pregnancy.

MR imaging of the dizygotic sibling diagnosed with autistic disorder was obtained in order to identify whether structural brain development was altered, compared with what is normally expected. These structural differences were interpreted in light of programmed neural development, the impact of endocrine system changes on foetal central nervous system development, and the consequent expression of autism.

Blood plasma pathology analyses were obtained, using blood plasma samples of both dizygotic siblings. Blood plasma pathology reports complemented the enquiry into the pathogenesis of autism as a neurobiological developmental disorder, since endocrine system changes might have contributed to disruption of programmed neural development, and these plasma differences between siblings might continue to be present postnatally.

\section{The case study}

Outlines of the clinical data of the mother as well as the obstetric and developmental data of the dizygotic twins are presented in the following paragraphs. The maternal clinical history is dealt with under the headings gestational period, blood pressure readings, blood plasma pathology reports and recorded stressors.

\section{Gestational period}

At the time of pregnancy the mother was 31 years old, with no prior family history of autism or other psychiatric disorders. No medical conditions were diagnosed prior to conception, although the mother reported two previous miscarriages. The mother first 
consulted the gynaecologist at five weeks of gestation. Folic acid, multivitamins, calcium, magnesium and Asic (Pharmaceutical Enterprises Pty Ltd) were prescribed during pregnancy. Asic was administered to treat nausea during early pregnancy, and the active ingredients are dicyclomine HCI $10 \mathrm{mg}$, doxylamine succinate $10 \mathrm{mg}$ and vitamin $\mathrm{B}_{6} 50 \mathrm{mg}$ (Snyman, 2002). The prescribed dosage is two tablets at bedtime. Asic is a schedule 2 drug and the manufacturer published anticholinergic and central nervous system interaction as side effects of Asic administration (Snyman, 2002).

\section{Blood pressure readings}

During the course of the pregnancy, maternal blood pressure readings ( $\mathrm{mmHg}$ ) were recorded at monthly intervals, followed by two-weekly recordings during the third trimester, as presented in Table 1. Fluctuations in blood pressure recordings were compared with the World Health Organization's normal blood pressure values (MicroLife Group Africa, 2004).

$\begin{array}{lrr}\begin{array}{l}\text { Week of } \\ \text { gestation }\end{array} & \begin{array}{c}\text { Systolic blood pressure Diastolic blood pressure } \\ (\mathrm{mmHg})\end{array} & \begin{array}{c}\text { Measure } \\ \text { 5th week }\end{array} \\ \text { 10th week } & 100 & 60 \\ \text { 14th week } & 100 & 50 \\ \text { 18th week } & 110 & 50 \\ \text { 22nd week } & 110 & 60 \\ \text { 26th week } & 110 & 60 \\ \text { 28th week } & 110 & 60 \\ \text { 30th week } & 100 & 70 \\ \text { 32nd week } & 130 & 60\end{array}$

The mother's initial blood pressure readings were generally within the normal range when compared with the World Health Organization's normal blood pressure values (MicroLife Group Africa, 2004). However, blood pressure readings during the 10th and 14th week of gestation suggested a tendency towards hypotension, thereafter the blood pressure readings stabilised within the normal range, with a sudden upsurge of blood pressure during the 32nd week of gestation. Hypotension during the 10th and 14th week of gestation is suggested by blood pressure values that are too low (i.e., systolic values less than $100 \mathrm{mmHg}$ and/or diastolic values less than $60 \mathrm{mmHg}$ ). Hypotension might play a 
significant role in the ability of the placenta to maintain the foetus (i.e. provision of nutrients and removal of toxins), since proper development of the placental vascular system is essential to nutrient and gaseous exchange between the mother and developing embryo (Levitt et al., 1996; Huxley et al., 2000; Edwards et al., 2001a, b). These researchers have demonstrated that poor intra-uterine growth is associated with a reduced intra-uterine nutrient supply, which perturbs foetal growth and, concomitantly, alters or programmes the structure and function of developing systems. In this case, poor placental function was suggested by the mother's history of two previous miscarriages. Poor placental function might result in reduced foetal nutrient supply. Reduced placental nutrient supply might consequently expose the foetus to excess glucocorticoids, which act to restrict foetal growth and to programme permanent changes in the neural, cardiovascular, endocrine and metabolic systems (Wood et al., 1987; Tangalakis et al., 1992; Robinson et al., 1994; Phillips et al., 1996; Edwards et al., 1999, 2001a, b; Hoet \& Hanson, 1999; Unno et al., 1999; Edwards \& McMillen, 2001).

\section{Blood plasma pathology reports}

In light of the elevated blood pressure readings, maternal blood plasma samples were collected and analysed during the 32nd week of gestation. The laboratory results were compared with normal range values, presented in Table 2. These blood plasma pathology results indicate an abnormally low red blood cell count and the presence of neutrophil leucocytes, which might reflect bleeding, tissue damage, bacterial infection, steroid therapy and pregnancy. Enduring stress might produce similar pathology results due to a compromised immune system, because the experience of stress affects cellular immunity, and is implicated in the immunobiology of autism. Human immune function is mediated by the release of cytokines, non-antibody messenger molecules, from a variety of cells of the immune system, and from other cells, such as endothelial cells. There are Th1 and Th2 cytokines. Autoimmune and allergic diseases involve a shift in the balance of cytokines toward $\mathrm{Th} 2$. The autoimmune aspect of autism has been related to excessive Th2 cytokines resulting, in part, from vaccination (Rabin, 1999). Cytokines stimulate cellular release of specific compounds involved in the inflammatory response. Stressinduced activation of the sympathetic nervous system and the sympathetic-adrenalmedullary and HPA axes lead to the release of cytokines (Rabin, 1999). Continued stress during gestation can alter healthy immune system functioning, thereby affecting cytokines and indirectly the development of monoaminergic circuits in the foetal brain (Jarskog et al., 1997). Teratogenic effects of chronic prenatal exposure to glucocorticoids can alter the monoamine turnover in the locus coeruleus and nucleus tractus solitarius (Peyronnet et al., 2002). In addition, enduring stress appears to affect ascending serotonergic projections into the hippocampus and a long-lasting increase in glucocorticoid receptors (Sapolsky, 1997). These reciprocal changes are implicated in a permanently altered HPA axis and consequently in the pathogenesis of autism as a developmental disorder. Blocking the response of the sympathetic nervous system by pretreating subjects in stressful experiments with adrenergic antagonists can reduce this 


\section{Table 2. Results of maternal blood plasma analyses during the 32nd week of gestation}

Test

Description Result Normal range

Full blood count

Haemoglobin count

$12.0-16.0 \mathrm{~g} / \mathrm{dl}$

Red cell count

Low

3.91

4.00-5.00 1012/1

Haematocrit (anaemia)

36.3

$36-46 \%$

Mean corpuscular volume

92.9

80-100 fl

Mean corpuscular

haemoglobin

31.1

27-32 pg

Mean corpuscular

haemoglobin

33.4

$32.0-35.0 \mathrm{~g} / \mathrm{dl}$

concentration

Red cell distribution width

$11.7-13.6 \%$

White cell differential

count

White cell count

High

11.7

4.0-10.0 109/1

Neutrophil percentage

High

92.2

$50-70 \%$

Neutrophil absolute

High

10.80

$1.90-7.40109 / 1$

Lymphocyte percentage

Low

5.7

$20-40 \%$

Lymphocyte absolute

Low

0.70

1.00-4.50 109/1

Monocyte percentage

2.0

$2-8 \%$

Monocyte absolute

0.20

0.20-1.00 109/1

Eosinophil percentage

0.1

$1-4 \%$

Eosinophil absolute

0.00

0.00-0.50 109/1

Basophil percentage

0.0

$0.5 \%$

Basophil absolute

0.00

0.00-0.10 109/1

Platelet count

175

140-450 109/1

Erythrocyte sedimentation rate

$1-20 \mathrm{~mm} / \mathrm{h}$

Full blood count comments

Neutrophil leucocytes present-may reflect surgery, bleeding, tissue damage, bacterial infection, steroid therapy and pregnancy

Note: Low/high $=$ abnormal results.

Source: Values provided by Du Buisson, Bruinette and Kramer (Incorporated)

Pathologists, South Africa. 
release of cytokines and decrease the resulting inflammatory response (Benschop et al., 1994; Bachen et al., 1995). Discrete areas of the brain (e.g. the hypothalamus and the locus coeruleus) regulate the sympathetic nervous system and therefore the levels of circulating adrenergic stress hormones, thereby influencing the activity of the immune system (Wetmore \& Nance, 1991; Rassnick et al., 1994). Adrenergic stress hormones alter the synthesis and release of cytokines by white blood cells (leukocytes) as implicated by the preceding blood plasma pathology results presented in Table 2.

\section{Recorded stressors}

Three interviews were conducted with the parents: a joint interview with both parents present, and two individualised interviews with the mother and father separately. These self-reportings, together with the results of the 16-Personality Questionnaire, were analysed to construct a relatively reliable estimate of the stressors the mother was enduring at the time of conception, as well as during the postnatal period. The results are now reported under separate headings.

\section{Social and occupational stressors}

There were four main factors:

- The maternal grandmother was diagnosed with breast cancer four weeks prior to conception.

- The mother switched jobs (from education to private sector) about seven weeks prior to conception.

- Starting a new career then, both parents reported extreme levels of occupational stress during pregnancy. In addition, her new full-time occupation required the mother to drive very frequently almost every day, which she experienced as very stressful.

- Both parents reported extreme stressors associated with the husband's occupation for the duration of the pregnancy.

The interpretation is that psychological stress inhibits many aspects of the immune response, including innate immunity (e.g. natural killer cell lysis), T-cell responses and antibody production (Rabin, 1999). Cohen and co-workers administered a questionnaire for stressful life events, and low-immunity subjects scored higher for stressful life events. They showed higher perceptions of stress and more negative emotional experiences were associated with a greater likelihood of developing a clinical illness, defined as cold symptoms concomitant with isolating an infectious virus or developing a fourfold increase in antibody titres (Cohen et al., 1998). This corresponded with recorded stressors and blood plasma pathology results of this case study. In a second study by the same researchers, a life-stress interview replaced the questionnaire. This technique allowed the specification of the types of stressful events that increase risk. These included chronic events (lasting a month or longer), especially chronic social conflicts and 
underemployment or unemployment (Cohen et al., 1998). The results demonstrated a relationship between psychological stress and susceptibility to a compromised immune system. Outside proven clinical interventions, there is reason to think that certain changes in lifestyle might increase an individual's resistance to infectious diseases. These include broadening one's social involvements (e.g. joining social or spiritual groups, having a confidant, spending time with supportive friends) and being more careful to maintain healthy practices such as proper diet, exercise and adequate sleep, especially under stressful conditions (Cohen et al., 1997).

\section{Predisposition for stress tolerance due to personality structure}

The 16-Personality Factor Questionnaire was administered with the mother, and the

Table 3. Summary of the maternal 16-Personality Factor Questionnaire standardized sten scores

Low score description

MD Low motivational distortion

A Reserved

B Concrete thinking

C Affected by feelings

E Submissiveness

F Desurgency (sober)

G Superego weakness

H Shy

I Tough-minded

L Trusting

M Practical

$\mathrm{N}$ Forthright

O Self-assured, placid

Q1 Conservatism of temperament, tolerant of traditional difficulties

Q2 Group-dependency

Q3 Weak self-sentiment integration, lax

Q4 Low ergic tension, relaxed
12345678910 High score description

High motivational distortion

- $\quad$ Outgoing

- Abstract thinking

- Emotional stable

Assertiveness

Surgency

Superego strength

Adventurous

- $\quad$ Tender-minded

- Suspicious

- Imaginative

Shrewdness

Guilt proneness, Apprehensive

Radicalism, experimenting, analytical Self-sufficiency High strength of selfsentiment, controlled High ergic tension, tense, frustrated, driven 
results are summarised in Table 3. Considering the preceding 16-Personality Factor Questionnaire results (expressed as sten scores), the intention was not to provide an indepth personality analysis, but to consider only those factors that might have predisposed adverse psychological reaction to enduring stressors during pregnancy. As reflected in Table 3, significantly high scores were achieved on factors I, L and M, while significantly low scores were achieved on factors $\mathrm{N}$ and Q1. These scores will now be considered individually.Factor I measures the construct feeling versus thinking as contrasting modes of evaluating experiences (Cattell, 1989). The right pole (factor I+; sten score 8) is called premsia, a condensation for 'protected emotional sensitivity' (Cattell, 1989). In a nutshell, I+ individuals rely on their empathetic understanding to make evaluations; they are compassionate and sensitive as well as attuned to their own vulnerability. Cattell (1989) proposes that factor I+ might relate to right hemispheric specialisation, implicating that information is processed subjectively and emotionally. Heredity plays a significant role in factor I, and research findings demonstrated that genetics contributes $47 \%$ of the nature/nurture variance (Cattell, 1989). Stress-related illnesses, particularly of the coronary vascular system, are associated with factor I+ scores (Cattell, 1989, p. 169). The vascular system is thus implicated in poor placental functioning and spontaneous miscarriage.

Factor $\mathrm{L}$ measures the construct alienation versus identification in social orientations (Cattell, 1989). 'From a medical point of view, L+ scores are important indicators of proneness to stress, which shows most conspicuously by physical illness' (Cattell, 1989). Cattell also noted that high L+ scores are especially implicated in the onset of severe depression. Proneness to stress, which is associated with lowered immune system functioning and physical illness, might be linked to an increased release of cytokines as demonstrated by the mother's blood plasma pathology results (Benschop et al., 1994; Bachen et al., 1995).

Factor M measures the construct intuiting and sensing as contrasting perceptual modes (Cattell, 1989); that is, the temperamental proclivity to give either sensory data or ideational contents more immediate intensity. Once again factor $\mathrm{M}$ seems to relate to hemispheric specialisation, and individuals scoring high on factor $\mathrm{M}$ (factor $\mathrm{M}+$; autia) show a strong tendency to favour the use of the right hemisphere to respond emotionally and subjectively (like factor I+ scorers). 'M+ scorers' perceptions are diffuse and draw heavily on subliminal information, and these qualities, too, seem right-brained' (Cattell, 1989, p. 192). Cattell furthermore reported a high incidence of M+ scores among three major clinical syndromes; namely, substance abuse, schizophrenia and major depression. In addition, Cattell ( 1989) reported a high incidence of job dissatisfaction as primary complaint among high M+ scorers, suggesting poor tolerance for stress. Emotionality and job dissatisfaction were implicated as significant stressors during pregnancy by both the father and the mother (refer to earlier section 'Social and occupational stressors').

Factor $\mathrm{N}$ measures the construct self-presentation in social situations, and although there is no research on the genetic basis for factor $\mathrm{N}$, a combination of factor $\mathrm{N}-$ and $\mathrm{M}+$ 
characteristics suggests 'difficulty in dealing with social reality and in responding appropriately to interpersonal cues' (Cattell, 1989, p. 220), thereby implicating a heightened stress response.

Factor Q1 measures the construct orientation towards change (Cattell, 1989). Low Q1 scores (factor Q- scores) signal that the individual is likely to find it difficult to change. In addition, Cattell (1989) reported finding Q1- scores in the profiles of individuals with conversion hysteria, psychosomatic disorders and obsessive-compulsive disorders, suggesting poor tolerance for stress, avoidance of change and elevated levels of subjective anxiety. Surprisingly, this poor tolerance for stress is not toned down by higher intelligence (factor B+ scores) or by ego-strength (factor $\mathrm{C}+$ scores). In light of the mother's career change and difficulty to adjust to stressors associated with a new career, these scores therefore also suggest a heightened stress response during pregnancy.

The preceding results of the personality scale thus suggest a maternal predisposition for poor stress tolerance, in keeping with recorded stressors reported earlier, and postpartum depression (reported as perinatal and postnatal stressors below). Poor stress tolerance is associated with elevated stress hormone levels, implicating lowered immunity as suggested by the blood plasma pathology results.

\section{Perinatal and postnatal stressors}

The mother met the full diagnostic criteria for postpartum depression (APA, 2000), for which she was treated for a period of one year following the birth of the twins.

\section{Dizygotic twin obstetric and developmental data}

In the 32nd week of gestation the mother presented with premature contractions and a Caesarean section was indicated. A female foetus of $2.1 \mathrm{~kg}$ and a male foetus of $1.98 \mathrm{~kg}$ were delivered, with an Apgar count of 9/10 each. No birth defects were noted at the time of delivery.

At about three years of age, a paediatrician in private practice (Pretoria, South Africa) diagnosed the dizygotic twin boy with autistic developmental disorder, since on applying the diagnostic criteria for autistic disorder set out in the DSM-IV-TR (APA, 2000), the boy met the autistic triad (i.e. compromised socialisation, communication and imagery), with sparing of visual-motor abilities. Habitual toe walking was also noted. This diagnosis was confirmed by an in-depth psychological assessment. Following the paediatrician's diagnosis, a psychologist specialising in autism again assessed the boy. The Childhood Autism Rating Scale (Schopler et al., 1992) was administered and the diagnosis of autism was confirmed. The Griffith Scales of Mental Development (Holford, 2000) were administered and a general quotient of 82 was calculated, which signified low-average intellectual functioning (APA, 2000). 


\section{Magnetic resonance imaging}

The subject is of slender physique, and presents with a head circumference of $51 \mathrm{~cm}$, compared with his twin sister's head circumference of $49.5 \mathrm{~cm}$, implicating enlarged head size despite his slender physique and lower birth weight compared with that of his twin sister. At ages two to four years a $10 \%$ greater brain volume represents a $1.5-\mathrm{cm}$ greater head circumference in children with autism as compared with typically developing controls (Bartholomeusz et al., 2002; Courchesne et al., 2003). Over the past 10 years MR imaging studies have consistently pointed towards increased brain volume in autism (Nicolson \& Szatmari, 2003). Children diagnosed with autism were found to have an overall $9.8 \%$ increase in cerebral volumes compared with typically developing children (Sparks et al., 2002). Research findings published by Courchesne (2004) suggest that increased brain volume in autism is associated with accelerated brain growth early in development, followed by arrested brain growth.

Furthermore, the subject's MR images revealed abnormalities with regards to the temporal lobe, the lateral fissure, the superior temporal gyrus and sulcus, as well as the rostrum of the corpus callosum. These brain abnormalities are implicated in the autistic triad; namely, compromised socialisation, communication and imagination (APA, 2000).

\section{The twins' blood plasma pathology reports}

Blood plasma samples were analysed to determine serotonin and cortisol levels in both the dizygotic twin subject and the dizogotic twin control. The results are presented in Table 4. These blood plasma pathology results point towards distinct variations in plasma profiles for the subject and the control. The subject's serotonin and cortisol levels were significantly higher compared with the plasma profile of the control. These results are in keeping with recent research findings implicating elevated levels of serotonin and cortisol among individuals diagnosed with autism. Teratogenic effects of chronic prenatal exposure to glucocorticoids appear to affect ascending serotonergic projections into the hippocampus and a long-lasting increase in glucocorticoid receptors (Sapolsky, 1997). These reciprocal changes are implicated in a permanently altered HPA axis and consequently in the pathogenesis of autism as a developmental disorder. In addition to the adverse effects of prenatal exposure related to elevated levels of glucocorticoids, it has also been shown to have deleterious effects on programmed neural development; that is, inhibition of neural stem cells, neurogenesis and migration (Challis et al., 2001; Edwards \& Burnham, 2001), resulting in regional overgrowth and undergrowth in some areas, with the greatest deviations seen in the superior frontal, inferior frontal and superior temporal sulci and the Sylvian (lateral) fissure of children with autism (Levitt et al., 2003). 


\section{Table 4. Summary of dizygotic twins' blood plasma pathology reports}

Test Result Range

Source: Values provided by Du Buisson, Bruinette and Kramer (Incorporated)

Pathologists, South Africa.

Subject (male, four years seven months)

Serotonin

Cortisol

$90-385 \mathrm{ng} / \mathrm{ml}$

Control (female, four years seven months)

Serotonin

Cortisol

$80-450 \mathrm{ng} / \mathrm{ml}$

$6-23 \mathrm{mcg} / \mathrm{dl}$

Serotonergic abnormalities have been reported in autism, specifically hyperserotonemia, as well as elevated blood serotonin in the first-degree relatives of children with autism (Leventhal et al., 1990; Leboyer et al., 1999; Piven \& Palmer, 1999; Chugani, 2004). Chugani (2004) furthermore proposed that serotonergic abnormalities during prenatal and early postnatal development might lead to reciprocal changes in thalamocortical connectivity, which results in a certain predisposition for autism. As indicated in the preceding paragraphs, this might result in altered programmed neural development and 'resetting' of the foetal HPA axis, because the normal negative feedback system that regulates normal homeostasis is permanently altered (Edwards et al., 1993).

\section{Discussion}

Evidence from animal studies suggested that experimentally induced anxiety in pregnant animals affects the psychological and behavioural characteristics of the offspring (Harper $\&$ Williams, 1974). These early research findings are supported by recent findings suggesting that prenatal stress might play a significant role in the pathogenesis of autism (Coleman, 1994; Schultz \& Klin, 2002; Nicolson \& Szatmari, 2003; Chugani, 2004). Findings flowing from this dizygotic twin study suggest elevated maternal stress prior to conception, as well as during gestation, as recorded by the parents of the dizygotic twins, and supported by the results of the 16-Personality Factor Questionnaire. Various protocols support subjectively experienced stressors, as implicated by abnormally elevated leucocytes and glucocorticoids identified by maternal blood plasma pathology reports. The presence of neutrophil leucocytes might reflect bleeding, tissue damage, bacterial infection and steroid therapy; however, constant stress might also produce similar pathology results due to a compromised immune system, because the experience of stress affects cellular immunity due to HPA-axis involvement. Furthermore, elevated glucocorticoids might permanently change the foetal HPA axis, resulting in elevated cortisol levels, even postnatally. Significant cortisol differences were noted in the blood plasma pathology results of the subject and the control. Elevated cortisol levels might also result in hyperserotonemia. Although the subject's serotonin level did not exceed range values, it did exceed the control measure. Furthermore, hyperserotonemia and 
elevated glucocorticoids are implicated in altered programmed neural development, as suggested by the subject's MR images. The brain regions implicated were demonstrated by previous research findings to result in the typical autistic triad (APA, 2000), suggesting that elevated stress during gestation might play a significant role in the pathogenesis of autism.

In addition to the preceding findings, the difference between the subject's birth weight of $1.98 \mathrm{~kg}$ and the control's birth weight of $2.1 \mathrm{~kg}$ suggests intra-uterine deprivation or suboptimal placental nutrient supply (Edwards et al., 2001a, b). Epidemiological studies have highlighted the potential importance of foetal adaptations to a poor intra-uterine environment for longer-term health outcomes (Barker, 1992; Huxley et al., 2000). Edwards et al. (2001a, b) proposed that the physiological, neuroendocrine and metabolic adaptations that enable the foetus to adapt to a period of intra-uterine deprivation might result in a permanent reprogramming of the developmental pattern of proliferation and differentiation events within key foetal tissue and organ systems and have pathological consequences in adult life. This view is based upon observations that suboptimal placental or maternal nutrient supply results in exposure of the foetus to excess glucocorticoids, which act to restrict foetal growth and programmed development (Hoet \& Hanson, 1999). In addition, proper development of the placental vascular system is essential to nutrient and gaseous exchange between the mother and the developing embryo. Philipp et al. (2002) demonstrated that $\alpha_{2}$-adrenoceptors-which are activated by adrenaline and noradrenalin-are important regulators of placental structure and function, supporting the current hypothesis that prenatal stress during certain critical gestational periods contributes to altered programmed development implicated in autistic disorder.

\section{Conclusion}

The presence of elevated glucocorticoids might permanently alter the foetal HPA axis, as suggested by elevated cortisol and serotonin levels in the subject, as well as various brain abnormalities. These findings thus suggest disrupted programmed foetal development as implicated in autistic disorder. Reflecting on the research hypothesis, it was demonstrated at hand of a dizygotic twin study that prenatal stress might have significantly contributed to the pathogenesis of autism, despite unexpected variables that might have interfered with the protocols, such as administration of Asic during early pregnancy. Therefore the research hypothesis is only provisionally accepted. The following conclusions were arrived at:

- The preceding findings suggest elevated maternal stress prior to conception, as well as during gestation.

- Enduring stress might have produced elevated leucocytes and glucocorticoids, because the experience of stress affects cellular immunity due to HPA-axis involvement in stress.

- The subject's elevated glucocorticoids suggested a permanently changed foetal HPA axis, resulting in postnatal elevated cortisol levels. 
- Significant cortisol differences were noted in the blood plasma pathology results of the subject and the control, suggesting that elevated cortisol resulted in hyperserotonemia.

- Hyperserotonemia and elevated glucocorticoids are therefore implicated in altered programmed neural development, as suggested by the subject's MR images.

- The difference between the subject's birth weight of $1.98 \mathrm{~kg}$ and the control's birth weight of $2.1 \mathrm{~kg}$ suggests intra-uterine deprivation or suboptimal placental nutrient supply, which manifested differently among the dizygotic twins (because they did not share the same placenta).

- The subject presented with a head circumference of $51 \mathrm{~cm}$, compared with his twin sister's head circumference of $49.5 \mathrm{~cm}$, implicating enlarged head size despite his slender physique and lower birth weight compared with that of his twin sister. At ages two to four years, a 10\% greater brain volume represents a $1.5-\mathrm{cm}$ greater head circumference in children with autism as compared with typically developing controls (Bartholomeusz et al., 2002; Courchesne et al., 2003).

These findings, however, are not conclusive, since unexpected variables entered the protocols (e.g. drug administration). Asic was administered to treat nausea during early pregnancy, and the active ingredients are dicyclomine HCI $10 \mathrm{mg}$, doxylamine succinate $10 \mathrm{mg}$ and vitamin $\mathrm{B}_{6} 50 \mathrm{mg}$ (Snyman, 2002). Asic is a schedule $2 \mathrm{drug}$ and the manufacturer published anticholinergic and central nervous system interaction as side effects of Asic administration (Snyman, 2002). Furthermore, these findings are based upon a single case study only.

\section{Recommendations}

It is recommended that prenatal primary health care regimes should include stressmanagement programs. Maternal blood plasma sampling should be routinely done as a means to monitor glucocorticoids and serotonin levels during pregnancy as a protective measure.

The relationship between the postnatal process of brain overgrowth and prenatal neural defects remain to be determined and should be further investigated. In addition, the prenatal stress hypothesis involved in the pathogenesis of autism should be refined by further research. Also, a reduced foetal nutrient supply might be a consequence of poor placental function, resulting in exposure of the foetus to excess glucocorticoids, which act to restrict foetal growth and to programme permanent changes in the neural, cardiovascular, endocrine and metabolic systems. The role and relationship between heightened stress during pregnancy, poor placental functioning and suboptimal placental nutrient supply in the pathogenesis of autism should be further investigated in more representative samples. 


\section{References}

1. Alvarez, P., Zola-Morgan, S. and Squire, L. (1995) Damage limited to the hippocampal region produces long-lasting memory impairment in monkeys. Journal of Neuroscience 15 , pp. 3796-3807

2. American Psychiatric Association (APA) (2000) Diagnostic and statistical manual of mental disorders (4th edn, text rev), APA, Washington, DC

3. Bachen, E. A., Manuck, S. B. and Cohen, S. (1995) Adrenergic block adeameliorates cellular immune responses to mental stress in humans. Psychosomatic Medicine 57 , pp. 366-372.

4. Barbazanges, A., Piazza, P. V., Le Moal, M. and Maccari, S. (1996) Maternal glucocorticoid secretion mediates long-term effects of prenatal stress. Journal of Neuroscience 16, pp. 3943-3949.

5. Barker, D. J. P. O'Brien, P. M. S., Wheeler, T. and Barker, D. J. P. (eds) (1992) Foetal programming and public health. Foetal programming: influences on development and disease in later life pp. 3-11. Royal College of Obstetrics and Gynaecology Press, London

6. Barlow, D. H. and Durand, V. M. (2002) Abnormal psychology (3rd edn), Wadsworth, Belmont, CA

7. Bartholomeuz, H. Z., Courchesne, E. and Karns, C. M. (2002) Relationship between head circumference and brain volume in healthy normal toddlers, children, and adults. Neuropediatrics 33 , pp. 239-241

8. Bauman, M. L. and Kemper, T. L. (1994) The neurobiology of autism Johns Hopkins University Press, Baltimore, MD

9. Bauman, M. L. and Kemper, T. L. Panksepp, J. (ed) (1995) Neuroanatomical observations of the brain in autism. Advances in biological psychiatry pp. 1-26. JAI Press , Greenwich, CT

10. Benediktsson, R., Lindsay, R., Lindsay, R. S. and Seckl, J. R. (1993)

Glucocorticoid exposure in utero: a new model for adult hypertension. Lancet 341 , pp. 339-341.

11. Benschop, R. J., Nieuwenhuis, E. E. S., Tromp, E. A. M., Godaert, G. L. R., Ballieux, R. E. and Van Doornen, L. J. P. (1994) Effects of beta-adrenergic blockade on immunologic and cardiovascular changes induced by mental stress. Circulation 89 , pp. 762-769. 
12. Bertram, C. E. and Hanson, M. A. (2002) Prenatal programming of postnatal endocrine responses by glucocorticoids. Reproduction 124 , pp. 459-467

13. Beversdorf, D. (2004) Major stress during pregnancy linked to autism Ohio State University Medical Center - Available online at: http://0-www.acs.ohiotate.edu.innopac.up.ac.za/units/research/archive/preterm.htm (accessed 6 May 2004)

14. Burd, L. (1999) Month of birth of non-speaking children. Developmental Child Neurology 30 , pp. 685-686.

15. Byrne, C. D. (2001) Programming other hormones that affect insulin. British Medical Bulletin 60 , pp. 153-173.

16. Cattell, H. B. (1989) The 16-PF: personality in depth Institute for Personality and Ability Testing, Inc., Champaign, IL

17. Challis, J. R. G., Sloboda, D., Matthews, S. G., Holloway, A., Alfaidy, N., Howe, D., Fraser, M., Moss, T. J. M. and Newnham, J. (2001) The foetal placental hypothalamic-pituitary-adrenal axis, parturition and post natal health. Molecular and Cellular Endocrinology 185 , pp. 135-144.

18. Chugani, D. C. (2004) Serotonin in autism and pediatric epilepsies. Mental Retardation and Developmental Disabilities Research 10 , pp. 112-116. 19. Clark, G. D. (2002) Brain development and the genetics of brain development. Neurologic Clinics 20 , p. 4.

20. Cohen, S., Doyle, W. J., Skoner, D. P., Rabin, B. S. and Gwaltney Jr., J. M. (1997) Social ties and susceptibility to the common cold. The Journal of the American Medical Association 277 , pp. 1940-1944

21. Cohen, S., Frank, E., Doyle, W. J., Skoner, D. P., Rabin, B. S. and Gwaltney Jr., J. M. (1998) Types of stressors that increase susceptibility to the common cold in adults. Health Psychology 17 , pp. 214-223.

22. Colbert, M. C. (2002) Retinoids and cardiovascular developmental defects. Cardiovascular Toxicology 2:(1), pp. 25-39.

23. Coleman, M. (1994) Second trimester of gestation: a time of risk for classical autism?. Developmental Brain Dysfunction 7:(2-3), pp. 104-109.

24. Courchesne, E. (2002) Anatomy and neurobiology of autism: abnormal early brain development in autism. Molecular Psychiatry 7 , pp. 21-23.

25. Courchesne, E. (2004) Brain development in autism: early overgrowth followed by premature arrest of growth. Mental Retardation and Developmental Disabilities Research Reviews 10 , pp. 106-111] 
26. Courchesne, E., Carper, R. and Akshoomoff, N. (2003) Evidence of brain overgrowth in the first year of life in autism. Journal of American Medical Association 290 , pp. 337-344.

27. Debier, C. and Larondelle, Y. (2005) Vitamins A and E: metabolism, roles and transfer to offspring. British Journal of Nutrition 93 , pp. 153-174.

28. Edwards, C. R. W., Benedicktsson, R., Lindsay, R. and Seckl, J. R. (1993)

Dysfunction of the placental glucocorticoid barrier: a link between the foetal environment and adult hypertension. Lancet 341 , pp. 355-357

29. Edwards, H. E. and Burnham, W. M. (2001) The impact of corticosteroids on the developing animal. Pediatric Research 50, pp. 433-440.

30. Edwards, L. J., Coulter, C. L., Symonds, M. E. and McMillen, I. C. (2001a) Prenatal undernutrition, glucocorticoids and the programming of adult hypertension. Clinical and Experimental Pharmacology and Physiology 28 , pp. 938-941.

31. Edwards, L. J. and McMillen, I. C. (2001) Maternal undernutrition increases arterial blood pressure in the sheep foetus during late gestation. Journal of Physiology 533 , pp. 561-570

32. Edwards, L. J., Simonetta, G., Owens, J. A., Robinson, J. S. and McMillen, I. C. (1999) Restriction of placental and foetal growth in sheep alters foetal blood pressure responses to angiotensin II and captopril. Journal of Physiology 515 , pp. 897-904.

33. Edwards, L. J., Symonds, M. E. and Warnes, K. E. (2001b) Responses of the foetal pituitary-adrenal axis to acute and chronic hypoglycaemia during late gestation in the sheep. Endocrinology 142 , pp. 1778-1785.

34. Eysenck, M. W. (2001) Principles of cognitive psychology Psychology Press, 2nd edn) (Hove)

35. French, N. P., Hagan, R., Evans, S. F., Godfrey, M. and Newnham, J. P. (1999) Repeated antenatal corticosteroids: size at birth and subsequent development. American Journal of Obstetrics and Gynecology 180 , pp. 114-121.

36. Gould, E. (1994) The effects of adrenal steroids and excitatory input on neuronal birth and survival. Annals of the New York Academy of Sciences 743, pp. 73-92.

37. Harper, J. and Williams, S. (1974) Early environmental stress and infantile autism. The Medical Journal of Australia 9 , pp. 341-346.

38. Herman, A. (1996) Neurobiological insights into infantile autism. The Harvard Brain 3 , pp. 19-24. 
39. Hoet, J. J. and Hanson, M. A. (1999) Intrauterine nutrition: its importance during critical periods for cardiovascular and endocrine development. Journal of Physiology 514 , pp. 617-627

40. Holford, L. (2000) Griffiths scales of mental development The Memorial Institute , Johannesburg — Unpublished report

41. Huxley, R. R., Sheill, A. W. and Law, C. M. (2000) The role of size at birth and postnatal catch-up growth in determining systolic blood pressure: a systematic review of the literature. Journal of Hypertension 18 , pp. 815-831.

42. Jarskog, L. F., Xiao, H., Wilkie, M. B., Lauder, J. M. and Gilmore, J. H. (1997) Cytokine regulation of embryonic rat dopamine and serotonin neuronal survival in vitro. International Journal of Developmental Neuroscience 15 , pp. 711-716

43. Kalat, J. W. (2001) Biological psychology (6th edn), Brooks/Cole , Pacific Grove, $\mathrm{CA}$

44. Kates, W. R., Burnette, C. P., Eliez, S., Strunge, L. A., Kaplan, D., Landa, R., Reiss, A. L. and Pearlson, G. D. (2004) Neuroanatomic variation in monozygotic twin pairs discordant for the narrow phenotype for autism. American Journal of Psychiatry 161 , pp. $539-546$

45. Keller, F. and Persico, A. M. (2003) The neurobiological context of autism. Molecular Neurobiology 28:(1), pp. 1-22.

46. Kolb, B. and Whishaw, I. Q. (2003) Fundamentals of human neuropsychology (5th edn), Worth Publishers, New York

47. Kurup, R. K. and Kurup, P. A. (2003) A hypothalamic digoxin-mediated model for autism. International Journal of Neuroscience 113 , pp. 1537-1559.

48. Leboyer, M., Philippe, A., Bouvard, M., Guilloud-Bataille, M., Bondoux, D., Tabuteau, F., Feingold, J., Mouren-Simeoni, M. C. and Launay, J. M. (1999) Whole blood serotonin and plasma beta-endorphin in autistic probands and their first-degree relatives. Biological Psychiatry 45:(2), pp. 158-163

49. Leventhal, B. L., Cook Jr., E. H., Morford, M., Ravitz, A. and Freedman, D. X. (1990) Relationships of whole blood serotonin and plasma norepinephrine within families. Journal of Autism and Developmental Disorders 20:(4) , pp. 499-511

50. Levitt, J. G., Blanton, R. E., Smalley, S., Thompson, P. M., Guthrie, D. and McCracken, J. T. (2003) Cortical sulcal maps in autism. Cerebellar Cortex 13, pp. 728-735. 
51. Levitt, N. S., Lambert, E. V., Woods, D., Hales, C. N., Andrew, R. and Seckl, J. E. (2000) Impaired glucose tolerance and elevated blood pressure in low birth weight, non-obese, young South African adults: early programming of cortisol axis. Journal of Clinical Endocrinology and Metabolism 85 , pp. 4611-4618.

52. Levitt, N. S., Lindsay, R. S., Holmes, M. C. and Seckl, J. R. (1996)

Dexamethasone in the last week of pregnancy attenuates hippocampal glucocorticoid receptor gene expression and elevates blood pressure in the adult offspring in the rat. Neuroendocrinology 64 , pp. 412-418.

53. Lindsay, R. S., Lindsay, R. M., Waddell, B. J. and Seckl, J. R. (1996) Inhibition of 1\&inodot;bHSD in pregnant rats and the programming of blood pressure in the offspring. Hypertension 27 , pp. 1200-1204.

54. Maden, M. (2001) Role and distribution of retinoic acid during CNS development. International Review of Cytology 209 , pp. 1-77.

55. Matthews, S. G. (2001) Antenatal glucocorticoids and the developing brain: mechanisms of action. Seminars in Neonatology 6 , pp. 309-317

56. McEwen, B. S. (1997) Possible mechanisms for atrophy of the human hippocampus. Molecular Psychiatry 2:(3) , pp. 255-262.

57. MicroLife Group Africa (2004) Blood-pressure values (units mmHG) according to World Health Organization - Available online at: http://microlife.com (accessed 6 December 2005)

58. Miller, L. A., Munoz, D. G. and Finmore, M. (1993) Hippocampal sclerosis and human memory. Archives of Neurology 50, pp. 391-394.

59. Naudé, H. Marx, J., Pretorius, E. and Hislop-Esterhuyzen, N. Evidence of early childhood defects due to prenatal over-exposure to vitamin A: a case study. Early Child Development and Care - in press

60. Nicolson, R. and Szatmari, P. (2003) Genetic and neurodevelopmental influences in autistic disorder. Canadian Journal of Psychiatry 48:(8) , pp. 526-537.

61. Nyirienda, M. J., Lindsay, R. S., Kenyon, C. J., Burchell, A. and Seckl, J. R. (1998) Glucocorticoid exposure in late gestation permanently programmes rat hepatic PEPCK and GR expression and causes glucose intolerance in adult offspring. Journal of Clinical Investigation 101 , pp. 2174-2181.

62. Panksepp, J. (1998) Affective neuroscience: the foundations of human and animal emotions Oxford University Press, New York 
63. Perrotta, S., Nobili, B., Rossi, F., Di Pinto, D., Cucciolla, V., Borriello, A., Oliva, A. and Della Ragione, F. (2003) Vitamin A and infancy: biochemical, functional, and clinical aspects. Vitamins and Hormones 66, pp. 457-591.

64. Peyronnet, J., Dalmaz, Y., Ehrstrom, M., Mamet, J., Roux, J. C., Pequignot, J. M., Thoren, H. P. and Lagercrantz, H. (2002) Long-lasting adverse effects of prenatal hypoxia on developing autonomic nervous system and cardiovascular parameters in rats. Pflugers Archives 443 , pp. 858-865.

65. Philipp, M., Brede, M. E., Hadamek, K., Gessler, M., Lohse, M. J. and Hein, J. (2002) Placental 2-adrenoceptors control vascular development at the interface between mother and embryo. Nature Genetics 31, pp. 311-315.

66. Phillips, I. D., Simonetta, G., Owens, J. A., Robinson, J. S., Clarke, I. J. and McMillen, I. C. (1996) Placental restriction alters the functional development of the pituitary-adrenal axis in the sheep foetus during late gestation. Pediatric Research 40 , pp. 861-866.

67. Phillips, D. I. W., Walker, B. R., Reynolds, R. M., Flanagan, D. E., Wood, P. J., Osmond, C., Barker, D. J. and Whorwood, C. B. (2000) Low birthweight predicts elevated plasma cortisol concentrations in adults from 3 populations. Hypertension 35, pp. 1301-1306.

68. Piven, J. and Palmer, P. (1999) Psychiatric disorder and the broad autism phenotype: evidence from a family study of multi-incidence autism families. American Journal of Psychiatry 56:(4) , pp. 557-563.

69. Plug, C., Meyer, W. F., Louw, D. A. and Gouws, L. A. (1987) Psychology dictionary (2nd edn), McGraw-Hill, Johannesburg

70. Rabin, B. S. (1999) Stress, immune function, and health: the connection WileyLiss and Sons Inc. , New York

71. Rassnick, S., Sved, A. F. and Rabin, B. S. (1994) Locus coeruleus stimulation by corticotropin-releasing hormone suppresses in vitro cellular immune responses. Journal of Neuroscience 14, pp. 6033-6040.

72. Robinson, J. S., Owens, J. A. and Owens, P. C. Thorburn, G. D. and Harding, R. (eds) (1994) Foetal growth and foetal growth retardation. Textbook of foetal physiology pp. 83-94. Oxford University Press , Oxford

73. Ross, S. A., McCaffery, P. J., Drager, U. C. and De Luca, L. M. (2000) Retinoids in embryonal development. Physiological Reviews 80:(3), pp. 1021-1054. 
74. Sapolsky, R. M. (1994) The physiological relevance of glucocorticoid endangerment of the hippocampus. Annals of the New York Academy of Sciences 743 , pp. 294-304.

75. Sapolsky, R. M. (1996) Stress glucocorticoids and damage to the nervous system: the current state of confusion. Stress 1, pp. 1-19. 76. Sapolsky, R. M. (1997) The importance of a well-groomed child [comment]. Science 277 , pp. 1620-1621.

77. Sapolsky, R. M. (2000) Glucocorticoids and hippocampal atrophy in neuropsychiatric disorders. Archives of General Psychiatry 57 , pp. 925-935.

78. Schmidt, C. and Rotenberg, J. S. (2005) Neurodevelopmental toxicology. Neurologic Clinics 23 , p. 2.

79. Schopler, E., Reichler, R. J. and Renner, B. R. (1992) The childhood autism rating scale Western Psychological Services , Los Angeles,

80. Schultz, R. T. and Klin, A. (2002) Genetics of childhood disorders: XLIII. Autism, part 2: neural foundations. Journal of the American Academy of Child and Adolescent Psychiatry 41:(10), pp. 1-5.

81. Shell, L. M. (1981) Environmental noise and human prenatal growth. American Journal of Physical Anthropology 56, pp. 63-70

82. Snyman, J. (2002) Mims desk reference 37 , South African Medical Association, Pinegowrie

83. Sparks, B. F., Friedman, S. D., Shaw, D. W., Aylward, E. H., Echelard, D. Artru, A. A. et al. (2002) Brain structural abnormalities in young children with autism spectrum disorder. Neurology 59:(2), pp. 1-14.

84. Squire, L. R. and Zola-Morgan, S. (1991) The medial temporal lobe memory system. Science 253 , pp. 1380-1386.

85. Stein, M. B., Koverola, C., Hanna, C., Torchia, M. G. and McClarty, B. (1997) Hippocampal volume in women victimized by childhood sexual abuse. Psychological Medicine 27:(4), pp. 951-959.

86. Tangalakis, K., Lumbers, E. R., Moritz, K. M., Towstoless, M. K. and Wintour, E. M. (1992) Effect of cortisol on blood pressure and vascular reactivity in the ovine foetus. Experimental Physiology 77 , pp. 709-717.

87. Trevarthen, C. (2000) Autism as a neurodevelopmental disorder affecting communication and learning in early childhood: prenatal origins, post-natal course and effective educational support. Prostaglandins, Leukotrienes, and Essential Fatty Acids 63:(1/2) , pp. 41-46. 
88. Unno, N., Wong, C. H. and Jenkins, S. L. (1999) Blood pressure and heart rate in the ovine foetus: ontogenic changes and effects of foetal adrenalectomy. American Journal of Physiology 276 , pp. 248-256.

89. Uno, H., Eisele, S., Sakai, A., Shelton, S., Baker, E., DeJesus, O. and Holden, J. (1994) Neurotoxicity of glucocorticoids in the primate brain. Hormones and Behaviour 28 , pp. 336-348.

90. Villareal, G. and King, C. Y. (2001) Brain imaging in posttraumatic stress disorder. Seminars in Clinical Neuropsychiatry 6:(2), pp. 131-145.

91. Wetmore, L. and Nance, D. M. (1991) Differential and sex-specific effects of kainic acid and domoic acid lesions in the lateral septal area of rats on immune function and body weight regulation. Experimental Neurology 113 , pp. 226-236.

92. Wood, C. E., Cheung, C. Y. and Brace, R. A. (1987) Foetal heart rate, arterial pressure, and blood volume responses to cortisol infusion. American Journal of Physiology 253 , pp. 904-909.

93. Young, S. N. (1996) Behavioral effects of dietary neurotransmitter precursors: basic and clinical aspects. Neurosience Biobehaviour Reviews 20 , pp. 313-323.

94. Zachman, R. D. (1995) Role of vitamin A in lung development. The Journal of Nutrition 125:(6), pp. 1634-1638.

95. Zola-Morgan, S. and Squire, L. R. (1993) Neuroanatomy of memory. Annual Review of Neuroscience 16 , pp. 547-563.

96. Zola-Morgan, S., Squire, L. R. and Ramus, S. J. (1994) Severity of memory impairment in monkeys as a function of locus and extent of damage within the medial temporal lobe memory system. Hippocampus 4, pp. 483-495. 